\title{
SOBRE A NOSSA TRADIÇÃO EXEGÉTICA E A NECESSIDADE DE UMA REAVALIAÇÃO DO ENSINO DE FILOSOFIA NO PAÍS ${ }^{1}$
}

Paulo Margutti (FAJE)

O desenvolvimento do presente tema envolve a resposta a duas questões fundamentais. A primeira delas é a seguinte: a pesquisa filosófica no Brasil vai bem? A resposta seria: de um modo geral, ela vai bem, se levarmos em conta os objetivos a que se propõe. A segunda questão é a seguinte: a situação da pesquisa filosófica no Brasil poderia melhorar? A resposta agora seria: sim, se mudarmos esses objetivos. O restante do presente texto será direcionado no sentido de justificar essa tese.

A pesquisa filosófica institucionalizada surgiu no Brasil apenas por volta de 1958, no Departamento de Filosofia da USP, depois de uma fase preparatória, em que o mesmo foi ocupado pelas Missões Francesas, de 1934 a 1957. Nessa fase inicial, cujos objetivos eram estabelecer as diretrizes básicas para o curso de Filosofia e formar os futuros docentes, o Departamento de Filosofia da USP esteve sob a influência direta de professores franceses como Maugüé, Granger, Guéroult e Goldschmidt, todos voltados para a análise das ideias com base na leitura rigorosa de textos filosóficos clássicos. A partir de 1958, a política pedagógica do Departamento foi desenvolvida não pelos catedráticos Cruz Costa e Lívio Teixeira, que abriram mão de suas prerrogativas, mas sim por docentes como Oswaldo Porchat, José Arthur Giannotti, Bento Prado Júnior

1 O presente texto corresponde a uma tentativa de reproduzir, com a maior fidelidade possível, as ideias apresentadas oralmente pelo Prof. Paulo Margutti por ocasião da mesa sobre Filosofia no Brasil, coordenada pelo Prof. Ivan Domingues, no XVII Congresso da Sociedade Interamericana de Filosofia, em Salvador, no dia 11/10/2013. Durante a escrita, porém, que exige um rigor maior de exposição, o autor infelizmente sucumbiu à tentação de fazer alguns acréscimos à sua fala original. Tais acréscimos, contudo, vão na mesma direção da tese original e apenas a complementam com mais detalhes. 
e Ruy Fausto. A pedagogia por eles utilizada "prescrevia para a graduação objetivos de formação técnica e crítica", num estilo de trabalho "centrado numa abordagem analítica da História da Filosofia, que visava dar ao aluno instrumentos teóricos para a compreensão das lógicas internas dos sistemas filosóficos". ${ }^{2}$ A preocupação fundamental do projeto pedagógico uspiano foi com o rigor dos estudos filosóficos, em oposição ao ambiente intelectual que dominava o país na primeira metade do século $\mathrm{XX}$, ambiente esse que os professores do Departamento de Filosofia consideravam caracterizado pela fluidez, pelo abuso da retórica e pela importação não crítica de novidades europeias. ${ }^{3}$ Não há espaço para discutir aqui essa avaliação do nosso ambiente intelectual na época, que poderia decorrer do pouco conhecimento que cronicamente temos da nossa própria evolução cultural. De qualquer modo, tudo indica que esse projeto pedagógico foi influenciado por uma autoimagem negativa do brasileiro enquanto filósofo, inspirada principalmente pelos trabalhos de Cruz Costa, para quem não existe uma Filosofia nacional. Ele pensa que isso é assim em virtude de nossa herança lusitana, marcada pelo caráter pragmático e antiespeculativo. Em seu clássico livro Contribuição à história das ideias no Brasil, Cruz Costa estuda fundamentalmente as transformações ou deformações das doutrinas europeias no Brasil, investigando as influências que elas exerceram no país. ${ }^{4}$ Em que pese o título, ele não faz propriamente uma história das ideias no Brasil, revelando antes uma atitude irônica de tipo socrático na análise de nossa evolução cultural, atitude essa que torna difícil classificar seu livro dentro das categorias tradicionais. Em que pese o interesse constante de Cruz Costa pela nossa realidade e pelo nosso pensamento, suas conclusões pessimistas a respeito da nossa capacidade filosófica contribuíram para desestimular os estudos posteriores da Filosofia brasileira. A partir da autoimagem negativa que ele nos oferece, podemos ser, no máximo, filosofantes. O brasileiro que pretende ir além disso e se tornar filósofo não passa de um autodidata apaixonado pelas novidades, voltado para o amadorismo ensaístico e para o intelectualismo superficial. Em virtude disso, a pedagogia proposta pelos colegas uspianos de Cruz Costa enfatizava o rigor da pesquisa para disciplinar a nossa mente inculta, capacitando-a para

2 Ver Histórico do Departamento, na página do Depto. de Filosofia da Faculdade de Filosofia, Letras e Ciências Humanas da USP. Disponível em: http://filosofia.fflch.usp.br/departamento/historico (Acessado em outubro de 2013).

3 Ver o Projeto Pedagógico do Departamento de Filosofia da FFLCH da USP. Disponível em: http://filosofia. fflch.usp.br/ departamento/projetoacademico (Acessado em outubro de 2013).

4 Ver CRUZ COSTA, J. "Contribuição à história das ideias no Brasil: o desenvolvimento da Filosofia no Brasil e a evolução histórica nacional”. 2ª ed. Rio: Civilização Brasileira, 1967. Introdução, pp. 3-12. 
o trabalho filosófico acadêmico sério, deixando a busca por elaborações mais pessoais e criativas para um momento posterior de nossa formação.

Nos últimos sessenta anos, esse projeto pedagógico serviu de paradigma para uma grande parte das instituições universitárias brasileiras, marcando assim o presente quadro da pesquisa filosófica no país. Esse quadro, todavia, apresenta no momento uma série de problemas que demandam uma pronta solução. Com efeito, embora a nossa mente filosófica rebelde tenha sido bastante disciplinada no período, a correspondente parte criativa da nossa atividade filosófica não teve a oportunidade de se desenvolver paralelamente. Em virtude disso, continuamos a fazer pesquisas concentradas em um único tema num único autor e nossas teses de doutorado pecam pela pouca originalidade. Em geral, essas teses têm três ou quatro capítulos, dos quais os dois ou três primeiros são eminentemente introdutórios, apresentando seja o contexto histórico do problema analisado, seja a moldura conceitual ligada ao problema. Essa parte prepara o palco para o que vem a seguir e por isso costuma ser uma mera repetição daquilo que um leitor bem informado sobre o assunto já deveria conhecer de antemão. Apenas um capítulo dessas teses, geralmente o último, apresenta um leve toque de criatividade para satisfazer, ainda que de maneira insuficiente, à exigência de que um trabalho de doutorado deva incluir originalidade sob a forma de uma transgressão pessoal. É claro que há exceções a esse quadro, mas elas são poucas e o que predomina é a situação descrita, em que o máximo de abertura para a criatividade está na possibilidade de elaborar uma interpretação original de um autor clássico. E esse objetivo foi atingido por diversos pesquisadores brasileiros. Outros porém, talvez por serem mais rebeldes, simplesmente abandonaram os estudos de Filosofia porque não suportaram as restrições que lhes foram impostas. Muitas e muitas vocações filosóficas autênticas podem ter sido ceifadas dessa maneira. Por esse motivo, a questão que se coloca é a de saber se o que tem sido feito até agora é suficiente em termos de atividade filosófica para um país como o Brasil.

Consideremos o problema dos critérios estabelecidos pela CAPES para avaliação dos nossos cursos de pós-graduação em Filosofia. Tais critérios se inspiram na pedagogia acima mencionada e por isso são muito rígidos, dificultando o aparecimento de qualquer forma mais criativa de fazer Filosofia no país. Na verdade, pensadores como Sócrates, Platão, Nietzsche e Wittgenstein não teriam seus trabalhos aprovados, caso fossem avaliados com os critérios da CAPES. Sócrates seria reprovado por falta de produção; Platão teria seus diálogos rejeitados, por adotar a forma fluida e retórica do diálogo; Nietzsche teria seus livros rejeitados, por abusar dos aforismos e dos argumentos ad 
hominem; Wittgenstein teria suas principais obras igualmente rejeitadas no caso do Tractatus, por desdizer a si próprio, recomendando um silêncio iluminado, e, no das Investigações, por adotar a forma de anotações esparsas, sem conexão aparente entre elas. Todos eles seriam também criticados por não revelarem qualquer preocupação com referências bibliográficas ou com notas de pé de página. Pior ainda, eles cometeram o grave erro de não revelar preocupação em repetir com rigor o que pensadores precedentes disseram, embora todos tenham se apropriado mais ou menos sem pudor das ideias relevantes de seus predecessores, adaptando-as aos seus próprios interesses teóricos. $\mathrm{Na}$ verdade, todos estavam preocupados em ir além das ideias que os precederam, ainda que isso fosse feito com o custo de alterar radicalmente alguma tradição em vigor. As ideias eram mais importantes do que o formato acadêmico de exposição das mesmas. Paradoxalmente, os estudos de filósofos clássicos como os mencionados são realizados no Brasil dentro de critérios acadêmicos rigorosos, como se as transgressões por eles cometidas pudessem ser convenientemente domadas e categorizadas por meio de investigações exegéticas capazes de desvendar seu sentido oculto. Com a pedagogia atual, foi criada no Brasil uma nova forma de escolástica, perpetuando a nossa tendência ibérica ao comentário, emblematicamente caracterizada pelo surgimento da Segunda Escolástica Portuguesa em plena Idade Moderna. Naquela época, adotando uma direção diferente daquela dos países do norte europeu, os lusitanos mantiveram a tradição medieval do comentário, por meio dos trabalhos de Pedro da Fonseca e João de Santo Tomás. Embora Pedro da Fonseca seja um aristotélico original, a tendência exegética por ele inaugurada nos inícios da Idade Moderna, tendência que marcou a Filosofia portuguesa por vários séculos, pode ser denominada fonsequismo. E o que a pedagogia implantada no Brasil na segunda metade do século XX fez foi retornar a essa tendência, embora sob uma nova forma. Com efeito, agora os pensadores interpretados não se reduzem aos grandes teóricos medievais, como Tomás de Aquino. Qualquer pensador de destaque, seja ele europeu ou norte-americano, pode ser objeto de estudo nessa nova escolástica. Mas o fonsequismo, ou seja, a nossa tendência ibérica ao comentário escolástico, continua ativo. Esse nosso pendor exagerado em direção à exegética já foi criticado mais de uma vez por pensadores estrangeiros que tiveram a oportunidade de participar de algum congresso de Filosofia realizado no Brasil. ${ }^{5}$ E vale a pena observar pessoais originais nos trabalhos apresentados por pesquisadores brasileiros num congresso em Goiânia, há alguns anos atrás. 
que as interpretações resultantes dessas investigações exegéticas, além de não fazerem qualquer referência à realidade brasileira, constituem em geral contribuições muito modestas e pouco significativas para as já autossuficientes Filosofias europeia e norte-americana. Sabemos que a grande ambição de muitos pesquisadores brasileiros da área de Filosofia é ter seus trabalhos publicados no exterior. Mas o risco que eles correm, quando oferecem alguma contribuição original, é o de terem seus nomes ligados não à História da Filosofia brasileira, e sim à História da Filosofia de um país estrangeiro. Esse é o caso de Roberto Mangabeira Unger, cujos trabalhos, escritos em inglês e voltados para o debate em voga nos Estados Unidos, levaram Cornell West a conferir-lhe um lugar de destaque na história do pragmatismo norte-americano de tipo profético. ${ }^{6}$

Os inconvenientes da situação em que nos encontramos foram diagnosticados inicialmente por Paulo Arantes, em 1994, no tex to $O$ bonde da Filosofia, que faz parte de seu livro Um Departamento Francês de Ultramar. ${ }^{7}$ Ali, ele mostra que o Departamento de Filosofia da USP se baseava na convicção de que a leitura dos clássicos constituía a única maneira de se aprender a filosofar. A adoção do estruturalismo fez do Departamento sobretudo um "método". Os alunos de um modo geral aceitavam esse figurino, mas todo ano aparecia um pequeno grupo de desenganados que queriam "filosofia" e não mero comentário de texto. Com o tempo, boa parte dos docentes estruturalistas se desinteressou pela verdade dos sistemas, preocupando-se fundamentalmente com a estrutura que articulava suas teses. Nas palavras de Arantes: "perguntava-se pelo sentido e não pela verdade de um sistema filosófico". ${ }^{8} \mathrm{O}$ resultado foi a adoção de "um método de inegável valor propedêutico e profilático, porém especializado em produzir o vácuo histórico em torno do discurso filosófico, cuja autonomia se devia preservar". ${ }^{9}$ É certo que o método evitava o achismo, o dogmatismo e a paixão pelas novidades, além de propiciar um senso das ideias gerais e uma desenvoltura na abstração. Mas havia um preço a pagar por isso, uma vez que a interpretação fiel dos textos trazia consigo não só a identificação com o respectivo autor, mas também a repetição pura e simples do que ele já tinha dito. Como consequências pedagógicas, foram instituídos os cursos monográficos e abandonadas as visões panorâmicas. Além disso, a polêmica filosófica se tornava desnecessária, dada a irrefutabilidade e

6 Ver WEST, C. "The American Evasioin of Philosophy: a Genealogy of Pragmatism". Madison, Wisconsin: The Un. of Wisconsin Press, 1989. pp. 114-222.

7 ARANTES, P. E. “Um Departamento Francês de Ultramar”. São Paulo: Paz e Terra, 1994. pp. 13-60.

8 Ibidem, p. 18.

9 Ibidem, p. 19. 
perenidade dos grandes sistemas filosóficos. A receita era simples e eficiente: para prevenir os nossos vícios dogmáticos, convinha represar as nossas tendências especulativas, disciplinando-as por anos e anos de aprendizagem adequada. Mas esse excesso de prudência trouxe como resultado o fato de que "o método promovia um sistema de inibições, funcionando ao mesmo tempo como álibi e carapaça protetora. Temia-se o ridículo de parecer metido a besta num país de letras amenas". ${ }^{10}$ Não foi sem razão que o golpe de 1964 deixou os professores do Departamento de Filosofia da USP em paz, uma vez que não havia nada em seus trabalhos que pudesse despertar as suspeitas dos censores da época. "A Filosofia prosseguia assim no rumo de sempre: coração à esquerda, mas inibindo qualquer promiscuidade entre rigor e interesse". ${ }^{11}$ Isso não significa que não tenha havido alguma polêmica em âmbito nacional, mas o mesmo foi relativamente modesto. Quase ao final de seu texto, Paulo Arantes, de passagem, sintetiza em um parêntese conciso a atividade filosófica decorrente da aplicação rigorosa da metodologia estruturalista: "fechar-se em copas e estudar foi sempre nossa maior especialidade". ${ }^{12}$

Infelizmente, a lúcida autocrítica de Arantes não produziu qualquer desejo de modificação da pedagogia aqui discutida. As reações da comunidade filosófica podem ser medidas pelas reações de Roberto Schwarz, Bento Prado Júnior, José Arthur Giannotti e Oswaldo Porchat, seus colegas de Departamento, que se manifestaram a respeito do livro de Arantes em uma mesa redonda, realizada à época do lançamento do livro. Vale a pena relembrar aqui o teor das discussões. Os textos correspondentes foram publicados na revista Novos Estudos CEBRAP, em julho de 1994. Para Roberto Schwarz, a inspiração do livro de Paulo Arantes se encontra na obra Formação da literatura brasileira, de Antonio Candido, que descreve o desejo dos brasileiros por uma literatura própria. ${ }^{13}$ Para Bento Prado Junior, a ideologia pedagógica descrita por Paulo Arantes era bem adequada à circunstância brasileira, embora boa parte dos trabalhos resultantes obedecesse ao modelo historiográfico importado. Mas o que Paulo Arantes discute de fato é uma reflexão sobre o lugar da Filosofia no mundo contemporâneo. Nesse empreendimento de inspiração hegeliana, a conclusão é que a Filosofia já se realizou num passado recente e por isso deixou de ter sentido fazer Filosofia diretamente. ${ }^{14}$ Para Giannotti, Paulo

13 SCHWARZ, R. "Filosofia em formação". Novos Estudos CEBRAP, Nr. 39, pp. 238-42, jul. 1994.

14 PRADO JÚNIOR, B. "Uma obra essencialmente filosófica". Novos Estudos CEBRAP, Nr. 39, pp. 255-57, jul. 1994. 
Arantes estaria generalizando indevidamente uma experiência dele próprio ou de sua geração. Em seu texto, Giannotti considera que o panorama brasileiro revela apenas obsessões filosóficas e não obras que espraiem efetivamente uma problemática. Para superar essa falha, Paulo Arantes teria recorrido à transposição do esquema estrutural francês à nossa realidade, dando assim unidade à produção uspiana e criando um novo patamar a partir do qual todo o resto da Filosofia brasileira poderia ser reportado. Para comprovar sua tese, Giannotti contrapõe uma descrição de outros aspectos institucionais do Departamento e também uma descrição de sua própria experiência nessa mesma instituição, buscando assim revelar o caráter reducionista da exposição de Arantes, que teria separado o Departamento Francês de Ultramar do Departamento Real. Em sua argumentação, Giannotti afirma que o estruturalismo só se tornou uma questão vital para o Departamento de Filosofia da USP depois de sua volta ao Brasil, em 1951, e depois da volta de Porchat, em 1961, embora cada um tenha absorvido esse estruturalismo à sua própria maneira. Giannotti admite estar na época interessado na articulação estrutural do texto, mas afirma que era de fato fascinado pela metafísica ali expressa. E não concorda com a ideia de que o método estrutural provoca um vazio histórico ao redor do texto. Para ele, a articulação estrutural do texto constitui um ponto de partida indispensável para que se possa compreender o entorno histórico. Paulo Arantes teria reduzido o Departamento aos limites de seu método, para conciliar alguns traços da cultura paulista com alguns traços da experiência filosófica da USP na década de $1960 .{ }^{15}$ Para Porchat, a avaliação de Arantes pode ser prematura, pois talvez ele esteja fazendo a história de algo que ainda não aconteceu. Embora esteja aumentando, a produção filosófica brasileira ainda é muito pobre. Nessa perspectiva, Arantes teria produzido uma idealização, embora tenha corretamente destacado a importância cultural institucional das realizações do Departamento de Filosofia da USP. Em sua crítica ao livro, Porchat tem três reparos a fazer: ele trata de um objeto inexistente, ele não fundamenta o discurso crítico utilizado e adota uma postura antifilosófica. Essa última decorreria de uma concepção de Filosofia não como algo vivido, mas como algo que se estuda de fora. Isso seria resultado de um historicismo marxizante, "que curiosa e paradoxalmente se alia ao que há de pior na metodologia estruturalista da História da Filosofia e na sua ideologia". ${ }^{16}$

15 GIANNOTTI, J. A. “Um livro polêmico". Novos Estudos CEBRAP, Nr. 39, pp. 243-50, jul. 1994.

16 PORCHAT PEREIRA, O. "Um ensaio brilhante de um intelectual maduro". Novos Estudos CEBRAP, Nr. 39, pp. 251-4, jul. 1994. 
Como se pode ver pelas declarações acima, Schwarz não toca na questão do método pedagógico; Bento Prado se refere a ele de passagem, reconhecendo porém a sua adequação à circunstância brasileira; Giannotti contesta a descrição do Departamento e de sua pedagogia, mas acaba reconhecendo a importância do método estrutural na instituição a partir de 1951; Porchat argumenta na mesma linha, ao admitir que Arantes destacou a importância cultural institucional das realizações do Departamento na década de 1960. Em que pesem as diferenças nas avaliações do livro, todos concordam implícita ou explicitamente com a conveniência da pedagogia adotada pelo Departamento, sem manifestar qualquer intenção de alterá-la a curto ou a longo prazo. $\mathrm{O}$ próprio texto de Paulo Arantes fornece alguma inspiração para essa atitude, pois, embora mostre com clareza os problemas gerados pela pedagogia estruturalista, revela, em última instância, uma grande complacência para com a situação. Porchat revela ter percebido isso muito bem, quando comenta em seu texto: "Será que não estamos nos tornando um Departamento de Filosofia que, temeroso do seu não reconhecimento externo, se volta narcisisticamente sobre si mesmo e complacente exclama: “Ah, como somos bons!'? Seria bom rirmos de nós mesmos talvez um pouco mais. Paulo Arantes generosamente ri, talvez, de nós mesmos um pouco menos". ${ }^{17}$

Em sintonia com a intenção de rir um pouco mais, o próprio Porchat contribuiu com outro momento importante para o diagnóstico de nossa situação. Isso ocorreu no conhecido Discurso aos Estudantes sobre a Pesquisa em Filosofia, proferido aos alunos da USP em 1998, que tratou explicitamente de suas preocupações para com a pedagogia adotada no país. Nesse texto, Porchat parte da oposição entre pesquisa em Filosofia e pesquisa em História da Filosofia, alegando que apenas a última tem sido estimulada entre nós, com base no método estruturalista de estudo das obras filosóficas. Esse método é por ele descrito como a busca pela apreensão da lógica interna do sistema filosófico, deixando de lado as posições pessoais, num verdadeiro "esquecimento metodológico de si próprio". Mas Porchat questiona em seguida se a pesquisa em História da Filosofia é a melhor maneira de preparar o aluno para a prática da Filosofia, de modo a atender às expectativas daqueles que se dirigem ao curso de Filosofia movidos por uma intenção diferente daquela de tornar-se apenas um historiador do pensamento filosófico. A pedagogia estruturalista estaria contribuindo para estimular e concretizar essas expectativas ou estaria contribuindo para acabar com elas? Porchat se pergunta se já não se teria 
ido muito longe na orientação historiográfica em detrimento da compreensão filosófica de nós mesmos e do mundo. Ele pensa que já chegou a hora de mudar. ${ }^{18}$

Num espírito análogo ao da reação ao livro de Paulo Arantes, os colegas de Porchat não levaram muito a sério o seu questionamento, interpretando-o como mais uma das excentricidades em que ele é pródigo. Por algum tempo, as eventuais reuniões de coordenadores de pós-graduações em Filosofia, promovidas pela ANPOF, assumiram a distinção porchatiana entre pesquisa em História da Filosofia e pesquisa em Filosofia e debateram a questão. Mas o resultado foi a persistência da metodologia exegética estruturalista, seja por inércia, seja por adesão convicta da maioria. Atualmente, a distinção porchatiana parece ter perdido a força original, sendo vista apenas com leve tolerância pela comunidade filosófica. Em virtude disso, a prática da pesquisa em Filosofia, em sentido porchatiano, continua parecendo um alvo ainda muito distante no nosso horizonte cultural.

Algumas exceções, porém, começaram a aparecer, abrindo uma pequena janela para as modificações que se fazem necessárias. O próprio Porchat, por exemplo, foi além da pesquisa em História da Filosofia e passou a fazer pesquisa em Filosofia, criando no país uma nova escola filosófica, o neopirronismo. É interessante notar que sua adesão a essa forma de ceticismo decorreu da própria aplicação estrita do método estruturalista, mediante a qual se faz abstração da verdade do sistema em benefício de seu sentido, numa autêntica antecipação da epoché pirrônica. Em que pesem a mudança de Porchat em direção a fazer Filosofia, ao invés de meramente explicar textos, e o estabelecimento de uma nova escola filosófica no país, muitos de seus colegas ainda pensam que o "Aristóteles de Porchat" é melhor do que o "neopirronismo de Porchat". Não é o caso de discutir esse ponto aqui, mas o futuro certamente mostrará o equívoco dessa avaliação, do ponto de vista da Filosofia brasileira.

Cabe aqui observar que outros colegas de Porchat, como Giannotti, Bento e o próprio Paulo Arantes, entre outros dignos de nota, também foram além da pesquisa em História da Filosofia, produzindo contribuições originais, algumas mais voltadas para a problemática da Filosofia ocidental, como no caso de Giannotti, e outras mais voltadas para a problemática cultural brasileira, como no caso de Bento e Arantes. De qualquer modo, isso criou uma situação estranha,

18 Ver PORCHAT PEREIRA, O. "Discurso aos estudantes sobre a pesquisa em Filosofia. Gênero: provocatio". Dissenso - Revista de Estudantes de Filosofia, São Paulo, DF-FFLCH-USP, Nr. 2, pp. 131-140, $1^{\circ}$ Sem. 1999. 
em que os mestres se libertaram das restrições metodológicas estruturalistas, ao passo que os alunos continuaram a trabalhar nos limites estreitos dessas mesmas restrições. Como não há qualquer estímulo nem treinamento na argumentação em defesa de posições próprias, somente um ou outro intelectual mais independente consegue superar a barreira das restrições pedagógicas e produzir alguma coisa pessoal. A criatividade continua dificultada por barreiras exegéticas. Infelizmente, essa situação perdura até os dias de hoje.

Um ponto importante a ser destacado aqui é que as observações acima não devem ser compreendidas como envolvendo a rejeição radical do trabalho exegético em Filosofia. Na verdade, ele é importante para a investigação filosófica e deve continuar existindo. O problema é que ele não constitui a única alternativa disponível. O que está sendo criticado aqui é a esmagadora predominância desse tipo de trabalho entre nós. A atividade filosófica inclui toda uma gama de alternativas possíveis, como a exegese com pretensões à máxima fidelidade, a aplicação de uma perspectiva filosófica de um autor a um problema por ele não considerado, a elaboração pessoal criativa e autônoma etc. Essas são apenas algumas das maneiras possíveis de fazer Filosofia, as quais incluem até mesmo o apelo à literatura para expressar intuições filosóficas, como fazem Machado de Assis e Clarice Lispector, por exemplo, ou o apelo à ação concreta como forma de argumentar, como fazia Diógenes de Sínope, por exemplo. Nessa perspectiva, a questão que se coloca é a seguinte: até que ponto a rebelde mente brasileira deve continuar sendo disciplinada academicamente no sentido de explicar textos estrangeiros, sem qualquer preocupação com a nossa realidade e com a elaboração pessoal criativa e autônoma? Sessenta anos de disciplina já não seriam suficientes para que se possa passar para uma nova etapa, em que a criatividade seja efetivamente estimulada? Afinal de contas, se a rebelde e inculta mente brasileira ainda não estiver disciplinada depois de tanto tempo, ela jamais o estará. É certo que a mudança de postura sugerida aqui poderá levar ao aparecimento de elaborações que, embora pessoais, criativas e autônomas, possuam falhas facilmente reconhecíveis. Mas esse é o preço a ser pago pela mudança de atitude. É preciso ter a coragem de começar. Depois de algum tempo, as propostas filosóficas brasileiras poderão apresentar um grau de articulação bastante adequado para as nossas necessidades. Os exemplos dados pelos autores anteriormente mencionados, que conseguiram de algum modo se libertar dos grilhões exegéticos, apontam nessa direção.

$\mathrm{O}$ que teria de ser feito, para que uma mudança na nossa predominante pedagogia exegética pudesse acontecer? Porchat, em seu Discurso aos Estudantes de Filosofia, faz duas sugestões nesse sentido. Em primeiro lugar, ele recomenda a introdução de cursos e seminários, bem como a orientação 
de pesquisas não sobre as doutrinas de um autor, mas preferencialmente sobre problemas filosóficos contemporâneos. Os problemas filosóficos que interessam aos estudantes, principalmente os de Filosofia moral, também deveriam ser levados em conta. Em segundo lugar, ele recomenda que os alunos sejam estimulados o tempo todo a exprimirem livremente, nos seminários, aulas e trabalhos escolares, suas próprias opiniões sobre os temas tratados. Eles deveriam ser encorajados a ousar criticar até mesmo as grandes teses filosóficas dos pensadores clássicos, em que pesem os perigos do abominável achismo, tão temido pelos bem-pensantes brasileiros. Para justificar sua proposta, Porchat argumenta que a maioria esmagadora dos pensadores clássicos não foi formada numa historiografia estruturalista nem antes nem depois de produzirem suas obras. Ele lembra também que os gregos praticaram fundamentalmente a discussão filosófica sobre problemas que diziam respeito às preocupações efetivas de sua época. Essa postura, porém, não se restringe aos gregos, atravessando toda a História da Filosofia. Em todos os tempos, aprender a filosofar é aprender a debater teses, a sustentar pontos de vista próprios e a rebater pontos de vistas opostos. É claro que a opção por essa postura tornaria mais árdua a tarefa do professor, já que "ensinar a filosofar exige que se filosofe também". ${ }^{19}$

As sugestões de Porchat ainda são hoje bastante adequadas à nossa situação e poderiam ser complementadas como segue. Em primeiro lugar, se a Filosofia tem a ver com as preocupações efetivas das pessoas de uma dada cultura e época, então é necessário que aprofundemos o conhecimento do pensamento filosófico brasileiro, desde os inícios da colonização até os dias de hoje. Essa espécie de autoconhecimento é essencial para o desenvolvimento de uma Filosofia que parta da situação existencial concreta das pessoas. $\mathrm{Na}$ verdade, o que predomina no país é uma ignorância quase total a respeito da História da Filosofia brasileira. Pensadores importantes e independentes, como Mário Vieira de Mello, por exemplo, são completamente ignorados pela comunidade filosófica, mais interessada na interpretação de autores estrangeiros. Isso é agravado pela existência de uma autoimagem negativa a respeito da capacidade brasileira de fazer Filosofia, que contribuiu não só para a adoção da pedagogia estruturalista, mas também para a permanência da mesma entre nós. Graças a ela, surgem também falsos problemas, como o da existência ou não de uma Filosofia brasileira: temos Filosofia no Brasil ou Filosofia do Brasil? Essa autoimagem não resultou de estudos adequados 
do pensamento filosófico brasileiro, mas sim de uma postura dogmática a respeito da cultura filosófica no país, marcada por um pensamento colonizado que insiste em avaliar a situação brasileira com critérios europeus claramente inadequados para a nossa autocompreensão. Além disso, é preciso voltar o olhar não só para a Filosofia praticada no Brasil, mas também para a Filosofia praticada na América Latina ou por latino-americanos residentes em outros países, com pensadores como Walter Mignolo, Ofelia Schutte, Enrique Dussel e Susana Nuccetelli, entre outros, que pensam a nossa situação de maneira independente, utilizando categorias não europeias e preconizando uma atitude de respeito para com nossa alteridade. Nessa perspectiva, os trabalhos dos alunos deveriam incluir obrigatoriamente uma parte em que se posicionam a respeito do autor ou do problema filosófico estudado, incluindo referências a pensadores brasileiros e latino-americanos. Tais pensadores deveriam ser acessíveis gratuitamente pela internet, do mesmo modo que as revistas de Filosofia, que deveriam ser todas disponibilizadas na rede, ao invés de ficarem mofando em alguma estante de biblioteca. Com essas providências, os nossos alunos seriam estimulados a conhecer efetivamente a nossa realidade e a pensá-la de maneira mais independente.

Em segundo lugar, a questão da internacionalização deveria ser repensada. $\mathrm{Da}$ forma que está planejada, ela simplesmente irá comprometer irremediavelmente a nossa identidade cultural. Os trabalhos atuais, publicados em inglês e voltados para temas europeus ou norte-americanos, nada têm a ver com a realidade brasileira. Eles são a manifestação da mais completa submissão cultural a categorias e critérios externos. Não será por meio desses trabalhos que obteremos o reconhecimento internacional. Isso não significa, contudo, que a publicação de textos em inglês seja um empreendimento sempre equivocado. Uma coisa é escrever em inglês para denunciar o imperialismo cultural, como faz Walter Mignolo, e outra bem diferente é escrever em inglês para expressar o conformismo de um pensamento colonizado. Mas o problema no país é mais agudo, pois a própria língua portuguesa tem sido afetada. Hoje em dia, é possível observar certos textos, produzidos por alunos brasileiros brilhantes, que se revelam infestados de anglicismos: fenomenalismo por fenomenismo, representacionalismo por representacionismo etc. A pontuação e o estilo também fogem ao espírito da língua portuguesa, revelando o quão insidiosamente o pensamento colonizado está infiltrado na comunidade filosófica brasileira. Os partidários da pedagogia estruturalista se orgulham de ter contribuído para o desenvolvimento de uma terminologia filosófica em português, mediante traduções especializadas, baseadas no conhecimento rigoroso das línguas de origem e numa reflexão filológica competente. Essa 
tese é discutível, uma vez que a nossa língua já possuía uma terminologia filosófica bastante ampla desde a implantação da Nova Escolástica Portuguesa. Mesmo que a tese fosse verdadeira, restaria saber até que ponto a nova terminologia filosófica introduzida no país representaria não só a inclusão artificial de vocábulos estranhos ao espírito da língua portuguesa, mas também o fortalecimento de um complexo de inferioridade dos falantes do português em relação aos falantes de outras línguas filosóficas imperiais, como o inglês, o francês e o alemão. Isso aconteceria principalmente quando estão em jogo palavras estrangeiras de difícil tradução, que sugerem a ideia de que a inculta língua portuguesa não teria um vocabulário à altura das sutilezas envolvidas. Ora, do ponto de vista da expressão de conceitos filosóficos, cada língua tem vantagens e desvantagens. O alemão, por exemplo, tem, para aqueles que praticam a metafísica, a vantagem de ser uma língua bastante expressiva, já que basta acrescentar os sufixos heit ou keit a um substantivo para se obter um termo profundamente abstrato. Mas isso se torna uma desvantagem para os partidários da Filosofia analítica, já que o poder de abstração da língua alemã pode facilmente desencaminhar um pensador em direção à coisificação de entidades abstratas não existentes. O mesmo acontece com o português, que tem vantagens quando está em jogo a expressão de nossas práticas concretas e desvantagens quando está em jogo a expressão de teorias abstratas. Isso não torna a nossa língua inferior às imperiais, apenas marca a nossa especificidade. $\mathrm{Na}$ verdade, temos também palavras intraduzíveis em outras línguas, como saudade, além de distinções sutis que outras línguas são incapazes de expressar, como aquela entre ser e estar.

Em terceiro lugar, o problema aqui levantado deveria ser discutido intensamente pela comunidade filosófica brasileira, da qual uma parte significativa parece insatisfeita com a situação e desejosa de modificá-la. Torna-se necessário um debate franco e aberto, em que não só defensores da pedagogia estabelecida, mas também defensores de pedagogias alternativas possam ser ouvidos e alterações possam ser feitas. Temos de encerrar a fase da imposição de uma pedagogia única baseada em uma Filosofia única, pois isso é o oposto da autêntica atividade filosófica, que pressupõe a alteridade e a liberdade de expressão do próprio pensamento. Isso poderia levar a uma modificação nos critérios da CAPES e do CNPq para a avaliação e o apoio de programas de pesquisa em Filosofia, em direção a uma maior abertura pedagógica e teórica. $\mathrm{O}$ debate proposto poderia também contribuir para $\mathrm{o}$ término da cisão culturalmente esquizofrênica que tem marcado a comunidade filosófica brasileira por mais de meio século e a partir da qual os pesquisadores da área de Filosofia se dividem em pelo menos três grupos que funcionam 
como vasos não comunicantes: os que fazem exegese de autores estrangeiros, os que fazem exegese de autores luso-brasileiros e os que tentam elaborar propostas independentes. De certo modo, todos se ignoram solenemente, contribuindo para fazer do país uma autêntica comunidade de desconversação.

Esse conjunto de providências constitui o mínimo necessário para promover uma alteração da maneira pela qual está sendo praticada a Filosofia no país. Somente se as adotarmos poderemos superar essa já suficientemente longa etapa de estagnação exegética e de ausência de debate. A superação dessa situação deveria ser feita no espírito do provérbio latino mencionado por Porchat, em seu discurso de 1998, provérbio esse que ainda se revela atual cerca de quinze anos depois: errare humanum est, sed perseverare in errore diabolicum. ${ }^{1}$ 